\title{
Tenascin- $C$ and alpha-smooth muscle actin positive cells are increased in the large airways in patients with COPD
}

\author{
Magnus Löfdahl ${ }^{1 *}$, Riitta Kaarteenaho², Elisa Lappi-Blanco ${ }^{3}$, Göran Tornling ${ }^{1}$ and Magnus C Sköld
}

\begin{abstract}
Background: Chronic obstructive pulmonary disease (COPD) is characterized by inflammation and remodeling of the lungs. This results in alterations in extracellular matrix (ECM) and structural changes leading to airflow obstruction. We studied the expression of tenascin- $C(T n-C)$ and alpha smooth muscle actin $(\alpha-S M A)$, which act as a marker of myofibroblasts, in large airways from COPD patients. Our aim was to elucidate whether this expression correlated with smoking or with disease development.
\end{abstract}

Methods: Bronchoscopy was performed on 20 COPD patients (mean age 56 years; range 39-61; FEV1/FVC $<70 \%$ and FEV1 median 53\% (range 33-69) of predicted). Age and smoking matched smokers (S) without COPD ( $n=13)$ and age matched non-smokers (NS) $(n=14)$ served as controls. Bronchial mucosal biopsies were analyzed by immunohistochemistry. The distribution of Tn-C expression was assessed and graded in three levels, and the number of spindle shaped cells staining positive for $\alpha$-SMA were counted.

Results: Biopsies from COPD patients had more $(P<0.001)$ Tn- $C$ expression than the two control groups. A significantly $(P<0.05)$ increased number of spindle shaped cells expressing $\alpha$-SMA was observed in COPD patients compared with the controls. Smokers and nonsmokers did not differ in this respect. The expression of Tn-C correlated positively $(P<0.001)$ to the number of $\alpha$-SMA positive cells.

Conclusions: We demonstrate increased expression of Tn-C and $\alpha$-SMA positive cells in the large airways in COPD. This was not associated to smoking per se, but to the presence of airway obstruction. Our findings add new information regarding remodeling characteristics and highlight the large airways as a potential site for airways obstruction in COPD.

\section{Introduction}

Chronic obstructive pulmonary disease (COPD) is recognized as an important cause of morbidity and mortality [1], affecting $7-14 \%$ of all adults in the western world $[2,3]$. Tobacco smoking is identified as the most important risk factor, and the disease is associated with an abnormal inflammatory response in the lung [4].

Inflammation in COPD has been displayed at different levels within the bronchial three and in the lung parenchyma [5-7]. This inflammatory response is chronic in nature and has been associated with an increased level of profibrotic mediators such as transforming

\footnotetext{
* Correspondence: magnus.lofdahl@karolinska.se

'Dept Medicine, Division of Respiratory Medicine, Karolinska Institutet,

Karolinska University Hospital Solna. Stockholm Sweden

Full list of author information is available at the end of the article
}

growth factor $\beta$ (TGF- $\beta$ ) and epidermal growth factor (EGF) [8]. The major site of the airways obstruction in COPD is located in the small airways and the obstruction per se has been found to be associated with structural changes in the bronchioles and in the pulmonary parenchyma [9]. Fibrosis observed in the subepithelial region in the large airways is a hallmark of asthma [10] and has been shown to correlate to disease severity [11-13]. In COPD or in chronic bronchitis, some studies have shown no alteration in reticular basement thickness [14] whereas other studies have shown a thickening of the reticular basement membrane compared to controls $[11,15]$.

Tenascin-C (Tn-C) is an extracellular matrix glycoprotein involved in tissue remodeling. Its expression is increased in the airway wall in diseases characterized by

\section{Biomed Central}


remodeling such as asthma [16,17]. In addition, Tn-C has been shown to be increased in a number of other lung diseases associated with remodelling of extracellular matrix $(\mathrm{ECM})$, such as idiopathic pulmonary fibrosis (IPF), allergic alveolitis, sarcoidosis, asbestosis, cryptogenic organizing pneumonia (COP), tuberculosis, atypical mycobacteriosis, lung cancer, mesothelioma and inflammatory myofibroblastic tumor [18-20], Tn-C has also been reported to be expressed, during fetal development of the human lung [21] but not in healthy human adult lung. In many lung diseases but also during lung development, $\alpha$-smooth muscle positive cells ( $\alpha$-SMA), which were obviously myofibroblasts, were shown to produce most of the Tn-C mRNA [22,23]. Myofibroblasts are fibroblast-like cells that were discovered in the early 70 's [24]. These cells were initially defined in ultrastructural terms, with the essential features being stress fibers, well-developed cell-to-stroma attachment sites i.e. fibronexus and intercellular intermediate and gap junctions [25]. Microscopic studies demonstrated that these cells express aalpha-SMA, fibronectin and vimentin [26]. Nowadays myofibroblasts are supposed to be the elementary factors in the pathogenesis of IPF and cancers [27]. aalpha-SMA is the most commonly used marker for a myofibroblast, although not specific, since also smooth muscle and endothelial cells express this marker [28]. Vimentin is an intermediate filament which is virtually always present in mesenchymal cell lines or neoplasms. At the present, the ubiquity of vimentin in soft tissues limits its diagnostic use in differentiating cell types and it mostly serves as a positive specimen control [29]. Vimentin is also expressed in inflammatory cells [30].

Studies on $\mathrm{Tn}-\mathrm{C}$ expression from patients with COPD are sparse whereas other ECM proteins have been more extensively analyzed. Krakenberg and co-authors observed that fibronectin, collagens I, III and IV, laminin and hyaluronan were enhanced in lung tissues of COPD-patients [31]. On the other hand, a recent study by Gosselink et al revealed that fibronectin is decreased in small airways of COPD patients [32]. A previous experimental study using primary human lung fibroblasts cultured from patients with COPD and asthma showed that fluticasone propionate increased the expression of fibronectin but decreased the expression of $\mathrm{Tn}-\mathrm{C}$ whereas salmeterol neither affected fibronectin or Tn-C [33]. In our own recently published study precursors of collagen I and III were shown to have variable expression profiles in large and small airways of the patients with different stages of COPD [34].

Given the chronic nature of inflammation in COPD and the importance of structural changes for lung function impairment [35], our aim was to quantify measures of remodeling in the large airways in COPD compared to smokers and nonsmokers. We therefore hypothesized that the expression of $\mathrm{Tn}-\mathrm{C}$ is increased in COPD similarly to many other ECM proteins. Moreover, we wanted to analyze if the number of $\alpha$-SMA positive cells, which probable represent myofibroblasts, are increased in COPD. Cell-specific expression of Tn-C and $\alpha$-SMA was analyzed in whole bronchial biopsy tissue area, not only in the area of the basement membrane, and the immunohistochemical findings were correlated with the clinical data of the patients.

\section{Materials and methods}

\section{Patients and control subjects}

Twenty patients with COPD, aged 39-61 years (mean age 57) were recruited from the Division of Respiratory Medicine, Karolinska University Hospital Solna, Stockholm, Sweden (Table 1). All patients had a post bronchodilator $\mathrm{FEV}_{1} / \mathrm{VC}<70 \%$ and $\mathrm{FEV}_{1}<70 \%$ of predicted and a smoking history of more than ten pack-years. In the COPD group, three of the patients had quit smoking. These three ex-smokers had a post bronchodilator $\mathrm{FEV}_{1}$ of 1.06, 2.17 and 1.65 (L), and had quit, respectively, nine years, six months and ten years prior to the study entrance. None of the patients in the COPD group had clinical history or radiological signs of any other pulmonary disease than COPD. Age-matched smokers ( $\mathrm{n}=$ 13) without COPD and non-smokers $(\mathrm{n}=14)$ served as controls. The COPD patients and the control group of

Table 1 Characteristics and lung function data in COPD patients, smoking controls (S) and non-smoking controls (NS)

\begin{tabular}{|c|c|c|c|}
\hline & COPD & $\mathrm{S}$ & NS \\
\hline$N(n)$ & 20 & 13 & 14 \\
\hline Males (n) & 11 & 6 & 7 \\
\hline Age (years) & $56 \pm 5$ & $55 \pm 7$ & $57 \pm 4$ \\
\hline Pack-years (years) & 34 (24-43)\#\#\# & $36(27-37)++\dagger$ & 0 \\
\hline FEV1/FVC & $\begin{array}{c}0.54 \\
(0.38-0.52) \\
* * * \# \# \# \\
\end{array}$ & $\begin{array}{c}0.80(0.76- \\
0.81)\end{array}$ & $\begin{array}{c}0.84(0.83- \\
0.84)\end{array}$ \\
\hline FEV1/VC & $\begin{array}{c}0.48 \\
(0.52-0.62) \\
* * * \# \# \#\end{array}$ & $\begin{array}{c}0.79(0.75- \\
0.83)\end{array}$ & $\begin{array}{c}0.77(0.76- \\
0.80)\end{array}$ \\
\hline FEV1 (L) & $\begin{array}{c}1.58 \\
(1.22-1.94) \\
* * * \# \# \#\end{array}$ & $\begin{array}{c}2.89(2.71- \\
3.57)\end{array}$ & $\begin{array}{l}3.32(2.75- \\
3.94)\end{array}$ \\
\hline $\mathrm{FEV}_{1}$ (\% predicted) & 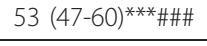 & $98(95-104) \dagger$ & $109(106-121)$ \\
\hline $\mathrm{FEV}_{1}$ reversibility (\%) & 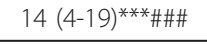 & $4(0-5)$ & $2(0-3)$ \\
\hline $\begin{array}{l}\mathrm{FEV}_{1} \text { reversibility } \\
(\mathrm{mL})\end{array}$ & 190 (75-265)\# & $90(0-170)$ & $70(8-105)$ \\
\hline
\end{tabular}

Data are shown as mean and standard deviation for age, mean and inter quartile range for pack-years, median and inter quartile range for all others. Significant difference between groups is marked with * (COPD vs HS), \# (COPD vs NS) and + (HS vs NS). The considered levels of significance were $P<$ 0.05 (*, \# or †), $\mathrm{P}<0.01$ (**, \#\# or $\dagger+$ ) and $\mathrm{P}<0.001$ (*** \#\#\# or †††). FEV1: Forced expiratory volume in one second, measured post bronchodilation; FVC: Forced vital capacity; VC: Vital capacity. 
smokers was matched regarding smoking history assessed as pack-years. All had a normal chest X-ray. No patient or control subject had a history suggesting allergy or asthma. All patients and controls were in a stable condition (i.e. none had a respiratory tract infection within three months prior to the study), and no participant had received oral or inhaled corticosteroids during the three months preceding the inclusion. Nine of the COPD patients used bronchodilator inhalers. Four of them had a short-acting beta-agonist inhaler, three had long-acting beta-agonist inhaler and two had a short-acting antimuscarinic inhaler. In addition, six patients used oral $\mathrm{N}$-acetylcysteine.

Each participant gave an informed consent and the study had the approval from the regional ethics committee, Karolinska University Hospital, Stockholm, Sweden, approval number: 99-319.

\section{Pulmonary function test}

All participants performed a dynamic spirometry in a standardized manner (Vitalograph ${ }^{\circledR}$, Buckingham, UK). Both slow vital capacity and forced vital capacity was performed, before and 10 minutes after inhalation with 2 doses of $0.5 \mathrm{mg}$ terbutalin (Bricanyl ${ }^{\circledR}$ Turbuhaler $^{\circledR}$; AstraZeneca, Södertälje, Sweden), and reversibility was calculated.

\section{Bronchoscopy and bronchial biopsies}

Bronchoscopy was performed as described previously [36]. Biopsy specimens were taken by use of pulmonary biopsy forceps with smooth edge jaws (Radial Edge ${ }^{(\mathbb{R}}$ Biopsy Forceps, Boston Scientific, Boston, MA). Four to six endobronchial mucosal biopsies were taken from each subject, and they were all collected from lobar or segmental carinae of the upper left lobe or the apical segment of the lower left lobe.

\section{Processing and immunohistochemical stainings of bronchial biopsies}

All biopsies were immediately formalin-fixed and embedded in paraffin. The material was evaluated, and representative tissue blocks from each case were selected for immunohistochemistry studies. Immunohistochemical stainings were performed as described previously $[20,22,23,35,37,38]$. Negative controls were obtained by using non-immune serum and PBS as substitute for the primary antibodies. Information of the antibodies used is shown in Table 2.

\section{Quantification of Tn-C and $\alpha$-SMA expression}

Two experienced pulmonary pathologists (RK and ELB) evaluated all biopsies. When analyzing the lung samples, both pathologists were blinded to the disease group status of the patients. 1-4 biopsy samples of each patient were analyzed, but for the statistics only one sample of
Table 2 List of the antibodies, concentrations and antigen-retrieval methods used in the study

\begin{tabular}{llll}
\hline Antibody & Source & Concentration & Antigen retrieval \\
\hline$\alpha$-SMA & Dako & 1:1000 & MW 19 min in tris-EDTA $\neq$ \\
\hline Desmin & Dako & 1:300 & MW 19 min in tris-EDTA \\
\hline Tn-C & Biohit & 1:1000 & MW 30 min in tris-EDTA \\
\hline Vimentin & Dako & 1:1500 & MW 14 min in citrate† \\
\hline
\end{tabular}

$\mathrm{MW}=$ microwave heat treatment; $\neq=$ tris/EDTA buffer, $\mathrm{pH} 9.0 ; \dagger=$ citrate buffer, $\mathrm{pH} 6.0$

each case was selected. The average area of the sections was 1-2 $\mathrm{mm}^{2}$, and the whole tissue section was analyzed by immunohistochemistry in each case. Immunohistochemical stainings for Tn-C and $\alpha$-SMA was performed in serial sections, i.e. in consecutive sections. Staining for desmin was done in 44 of the most representative cases for phenotyping the $\alpha$-SMA positive cells. In addition, vimentin was evaluated in 22 cases in which the tissue material was available.

The quantitative expression of $\mathrm{Tn}-\mathrm{C}$ was assessed in three categories. $T n-C(a)$ : staining present in basal epithelial cells and basement membrane of the bronchial epithelium; $T n-C(b)$ : staining present as in $T n-C$ (a) and in the stroma underneath the basement membrane; $T n-C(c)$ : staining present as in $T n-C(b)$ and in the wider area of the connective tissue of bronchial walls. Representative microphotographs for $\mathrm{Tn}-\mathrm{C}$ are displayed in Figure 1A-C.

The expression of $\alpha$-SMA was assessed in spindle shaped cells which were obvious myofibroblasts. Smooth muscle cells and cells of vessels were not scored. Quantification of the staining was assessed in four categories. $S M A$ (a): no cells; SMA (b): 1-4 cells; SMA (c): 5-10; $S M A(d):>10$ cells stained for $\alpha$-SMA. See Figure 1D-F for representative microphotographs of the expression of $\alpha$-SMA.

\section{Statistical analysis}

Descriptive data on the study population were analyzed by Kruskal-Wallis ANOVA and median test for differences between the three groups and by Mann-Whitney test for comparison between two groups.

To analyse differences on immunohistochemistry between the groups, we employed a proportional odds analysis for categorical data. For Tn-C, the two odds ratios $T n-C(a)$ vs. $T n-C(b+c)$ and $T n-C(a+b)$ vs. $T n-$ $C$ (c) were assumed to be the same within the pair wise comparison between the groups. For $\alpha$-SMA expression, the three odds ratios $S M A$ (a) vs. SMA ( $b$ $+c+d), S M A(a+b)$ vs. SMA $(c+d)$ and SMA $(a+b+c)$ vs. $S M A(d)$ were assumed to be the same within the pair wise comparison between the groups. The proportional odds model fits data well as demonstrated by the 


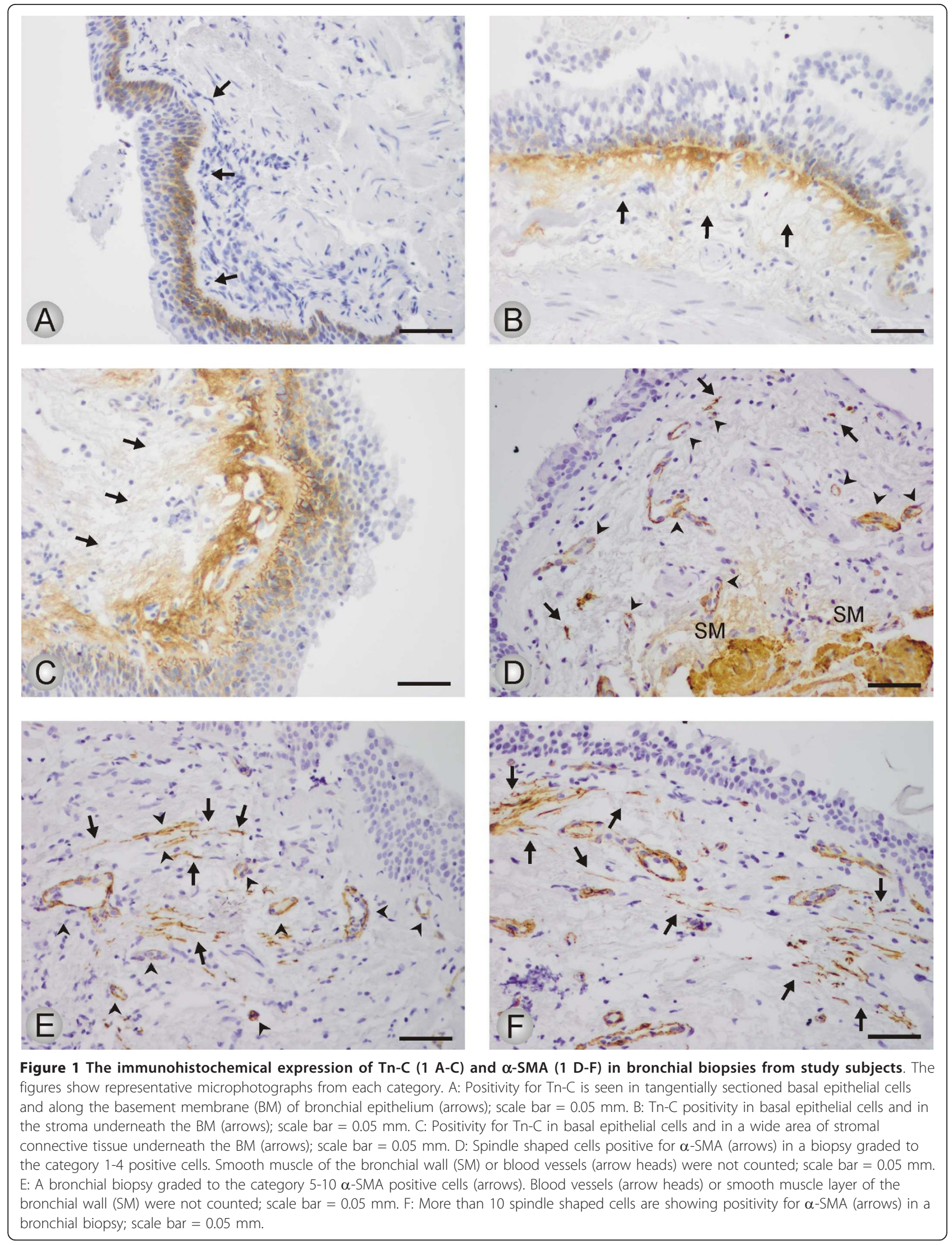


estimates being close to the observed frequencies. Test for homogeneity, i.e. no difference between all three groups, was statistically significant for both $\mathrm{Tn}-\mathrm{C}(\mathrm{p}=$ $0.003)$ and $\alpha$-SMA $(p=0.039)$, but since the difference between the HS and NS groups was small, we expressed the main effect by comparing the COPD group to HS and NS combined (geometric mean of the odds). Correlations between Tn-C and $\alpha$-SMA expression and lung function were calculated with Spearman's rank correlation coefficient.

A significance level of 5\% was applied for all statistical tests, and in case of a statistically significant result the probability value ( $\mathrm{p}$-value) is given.

\section{Results}

Immunohistochemistry for $\mathrm{Tn}-\mathrm{C}$

In general, Tn-C was expressed as extracellular thin and linear fibers underneath the bronchial epithelium and also in the wider area of connective tissue of the bronchial walls. All evaluated biopsies showed positivity for $\mathrm{Tn}-\mathrm{C}$ also in basal epithelial cells but the expression profile varied considerable between different patients. Representative microphotographs are shown in Figure 1A-C. The number and proportion of subjects within each staining category are presented in Table 3 and Figure 2. As shown, both the numbers of patients and the proportion of subjects expressing $\mathrm{Tn}-\mathrm{C}$ staining beyond basal epithelial cells and basal membrane, was higher in COPD patients compared to smokers and nonsmokers $(\mathrm{P}<$ 0.001). Of the three ex-smokers in the COPD group, two were in the lowest staining category $(a)$, and one in the intermediate (b).

\section{Immunohistochemistry for $\alpha$-SMA}

Spindle shaped $\alpha$-SMA positive cells were present in a proportion of subjects from all three study groups, representative microphotographs are shown in Figure 1D-F and Figure 3A. Out of the 44 cases with available stainings for desmin, 17 cases were spindle shaped cells positive both for $\alpha$-SMA and desmin, and 15 cases were spindle shaped cells positive for $\alpha-$ SMA but negative for desmin. In the remaining 12 cases no spindle shaped cells positive for either $\alpha$ SMA or desmin were found which finding indicate that those cases did not revealed any myofibroblasts. In the cases with spindle shaped cells positive for both antibodies, the desmin positive cells were always very few in numbers (Figure 3B). The $\alpha$-SMA positive smooth muscle cells and endothelial cells were excluded by their different location and morphology when compared to that of spindle shaped cells (Figure 3C-D).

The number and proportion of subjects within each staining category are presented in Table 3 and Figure 4. Presence of $\alpha$-SMA staining was observed in $83 \%$ of the COPD patients, in $46 \%$ of the smokers and in $41 \%$ of the nonsmokers. When data are presented as cumulative number and proportion of individuals with increasing number of cells stained positive for $\alpha$-SMA, COPD patients had significantly higher $(\mathrm{P}<0.05) \alpha$-SMA expression than smokers and nonsmokers.

Of the three ex-smokers in the COPD group, one was in category $(b)$, and two were in category (c).

\section{Immunohistochemistry for vimentin}

Regardless of the presence of $\alpha$-SMA or desmin positive spindle shaped cell, all cases expressed vimentin positive slender stromal cells. Most of them were probably fibroblasts of the subepithelial connective tissue (Figure 2E). In addition to this, all inflammatory cells stained positively for vimentin.

\section{Correlation between $\mathrm{Tn}-\mathrm{C}$ and $\alpha$-SMA}

The expression of Tn-C correlated positively to the expression of $\alpha$-SMA. The estimate for the correlation coefficient was 0.6; $\mathrm{P}<0.0001$ (Figure 5).

Table 3 The expression of Tenascin-C and $\alpha$-SMA in patients with COPD, smokers (S) and non-smokers (NS)

\begin{tabular}{|c|c|c|c|}
\hline & COPD & S & NS \\
\hline \multicolumn{4}{|l|}{ Tenascin C (Tn-C) } \\
\hline Number of acceptable biopsies & 20 & 12 & 14 \\
\hline Subjects expressing Tn-C only in basal epithelial cells and basal membrane, $T n-C$ (a) & $5(25 \%)$ & $9(75 \%)$ & $11(79 \%)$ \\
\hline Subjects expressing $T n-C$ as $T n-C$ (a) plus the stroma underneath basement membrane, $T n-C$ (b) & $10(50 \%)$ & $2(17 \%)$ & $3(21 \%)$ \\
\hline Subjects expressing $\mathrm{Tn}-\mathrm{C}$ as $\mathrm{Tn}-\mathrm{C}$ (b) plus wider expression within connective tissue, $\mathrm{Tn}-\mathrm{C}$ (c) & $5(25 \%)$ & $1(8 \%)$ & $0(0 \%)$ \\
\hline \multicolumn{4}{|l|}{$\alpha-S M A$} \\
\hline Number of acceptable biopsies & 18 & 13 & 12 \\
\hline Subjects with no cells expressing $\alpha$-SMA, SMA (a) & $3(17 \%)$ & $7(54 \%)$ & $7(59 \%)$ \\
\hline Subjects with 1-5 cells expressing $\alpha$-SMA, SMA (b) & $6(33 \%)$ & $2(15 \%)$ & $3(25 \%)$ \\
\hline Subjects with 5-10 cells expressing $\alpha$-SMA, SMA ${ }^{\odot}$ & $4(22 \%)$ & $3(23 \%)$ & $1(8 \%)$ \\
\hline Subjects with $>10$ cells expressing $\alpha$-SMA, SMA (d) & $5(28 \%)$ & $1(8 \%)$ & $1(8 \%)$ \\
\hline
\end{tabular}



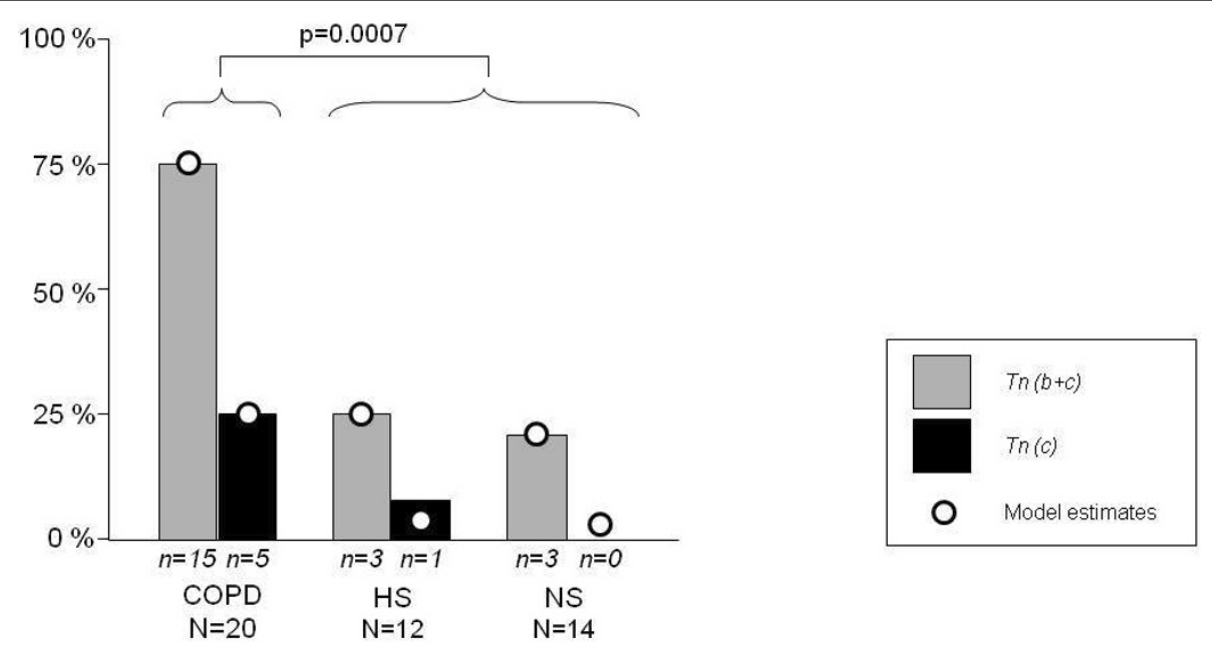

Figure 2 Number and proportion of subjects expressing Tenascin C outside the basal epithelial cells and basement membrane. Data is given for the three groups COPD, smoking controls (S) and non-smoking controls (NS). Tn C (b+c): All subjects with expression outside the basal epithelial cells and basement membrane. Tn $C^{\odot}$ : Subjects with expression within connective tissue beyond the stroma underneath basal membrane. The number $(n)$ of individuals in each category is presented underneath corresponding bar. The Odds ratio for a COPD patient to be in a higher category is statistically increased $(P<0.001)$ compared to subjects in the control groups.

\section{Correlations between Tn-C and $\alpha$-SMA expression and lung function parameters}

There was no correlation between the expression of Tn$\mathrm{C}$ or $\alpha$-SMA and any parameter of pulmonary function (data not shown).

\section{Discussion}

In this study, we investigated by immunohistochemistry the expression of $\mathrm{Tn}-\mathrm{C}$ and $\alpha$-SMA positive spindle shaped cells in bronchial mucosal biopsies as measures of remodeling of large airways in patients with COPD. We found that COPD patients had more expression of both Tn-C and $\alpha$-SMA positive cells compared to controls. In addition, there was a positive correlation between $\mathrm{Tn}-\mathrm{C}$ and $\alpha$-SMA expression. There were, however, no correlations between the expression of $\mathrm{Tn}$ $\mathrm{C}$ or $\alpha$-SMA and any lung function parameter.

Due to the differential immunohistochemical expression of Tn-C and $\alpha$-SMA we evaluated them in two different ways: Because the expression of $\mathrm{Tn}-\mathrm{C}$ was mainly extracellular and exhibited considerable variations between individual patients, its expression was analyzed by an applied semiquantitative method which took into consideration the specific cellular and histopathological localizations of the protein also in the areas around basement membranes. In contrast, $\alpha$-SMA expression was mainly intracellular also in those spindle shaped cells which were quantitatively counted in the present study. Both these evaluation methods are easily applied in routine clinical diagnostics since no extra equipments is needed. For further development of our grading systems the use of computer-assisted tomography might be beneficial. Our method has not been widely used and its repeatability may be lesser than 3-dimensional or 2dimensional methods described previously [39].

$\mathrm{Tn}-\mathrm{C}$ is a glycoprotein associated with tissue remodeling. In a study by Liesker et.al. [15], an increase in Tn$C$ expression in the large airways was seen both in COPD and in asthma patients. There was, however, no difference between COPD patients and a matched exsmokers control group. There are several differences between the study by Liesker et.al. and the present study. Firstly, our study has two control groups: smokers and non-smokers. Since there were no differences in Tn-C expression between smokers and non smokers in our study, we believe that the increased expression seen in the COPD group is associated with the disease, i.e. airways obstruction rather than exposure to tobacco smoke. Secondly, in our study, quantitatively more patients with a longer duration of smoking were investigated, and the COPD patients had a more severe airway obstruction. Finally, in our study all COPD patients except three were current smokers, and all subjects in the smokers control group were present smokers.

A previous study by Laitinen et.al.showed an increased expression of $\mathrm{Tn}-\mathrm{C}$ in the subepithelial layer of the basement membrane of patients with asthma when using immunofluorescence and morphometric methods for analyzing the bronchial biopsy samples [17]. The quantification method of $\mathrm{Tn}-\mathrm{C}$ in the present study was not similar to the study of Laitinen et.al. Since we analyzed the immunohistochemical expression of $\mathrm{Tn}-\mathrm{C}$ in the specific histological localizations of the airway mucosa instead of measuring it. Furthermore, we 


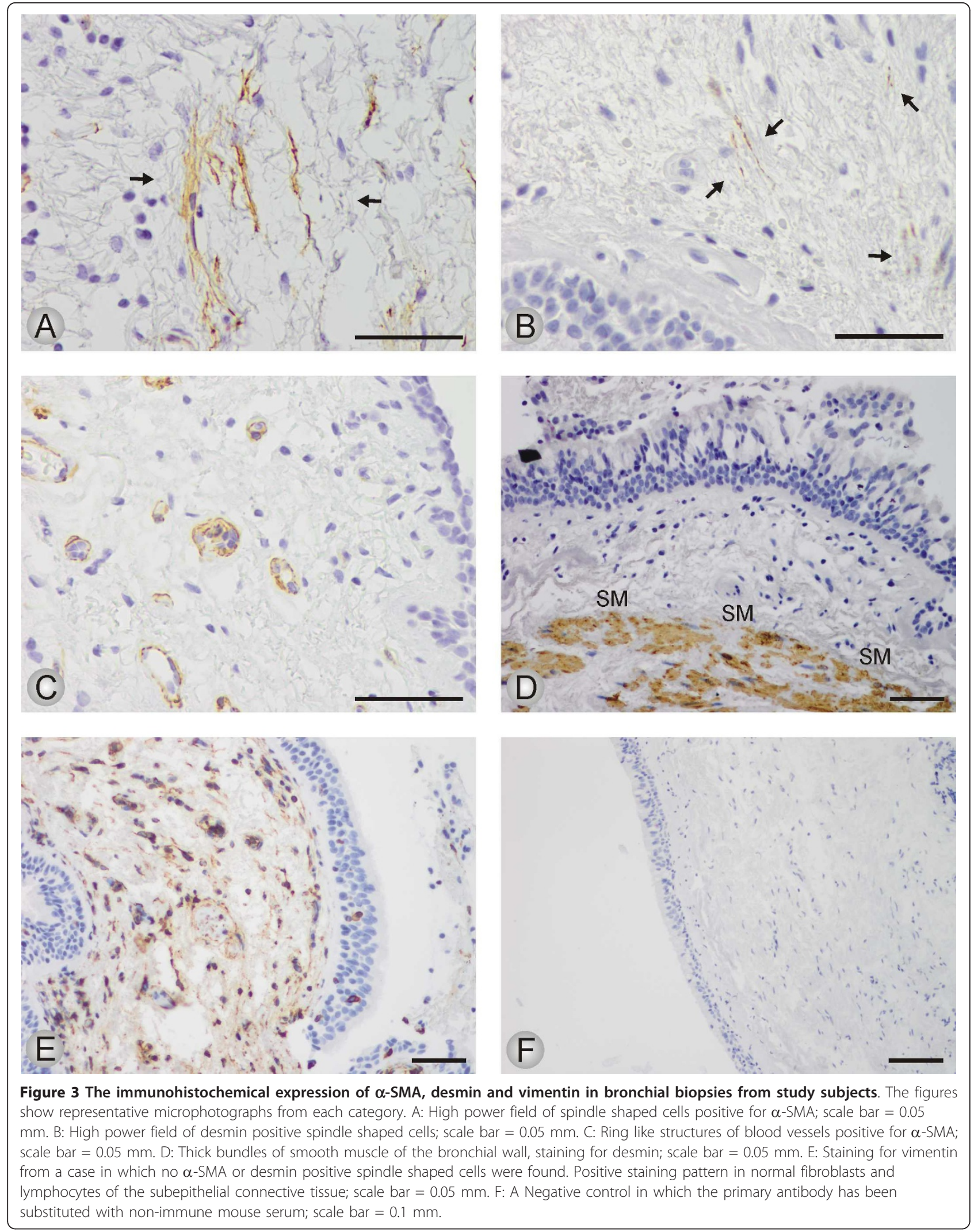




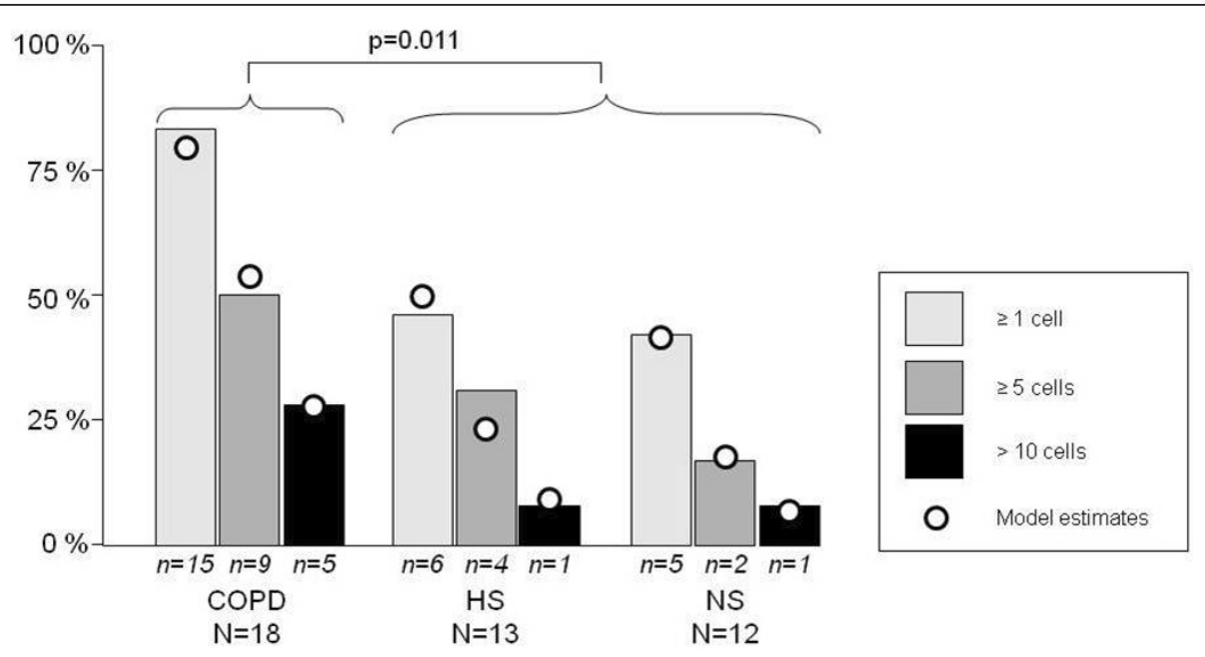

Figure 4 Number and proportions of subjects with cells staining positive for $\boldsymbol{\alpha}$-SMA. Data is given for the three groups COPD, smoking controls (S) and non-smoking controls (NS). The numbers ( $n$ ) of individuals in each category is presented as digits underneath each bar. The odds for a COPD patient to be in a higher category is statistically increased $(P<0.05)$ compared to subjects in the control groups.

observed that the staining for Tn-C beyond basal epithelial cells and basement membrane was higher in COPD patients compared to that of smokers and nonsmokers. The results of our study are somewhat similar to that particular study in that respect that in both studies the increase of $\mathrm{Tn}-\mathrm{C}$ seemed to be correlated with the remodeling process of the airways, and not to its trigger. To our knowledge, not much attention has previously been paid on $\mathrm{Tn}-\mathrm{C}$ expression outside the basement membrane area. We observed, however, that over 50\% of our COPD-patients showed an increased expression of $\mathrm{Tn}-\mathrm{C}$ beyond the basement membrane area. Laitinen and co-workers analyzed also the number of eosinophils and lymphocytes, but did not found any correlation between the amount of these inflammatory cells and the expression of $\mathrm{Tn}-\mathrm{C}$. In the present study we attempted to compare the number of $\alpha$-SMA positive spindle shaped cells, which were obviously myofibroblasts, with the amount of $\mathrm{Tn}-\mathrm{C}$ and found a positive correlation between these two markers.

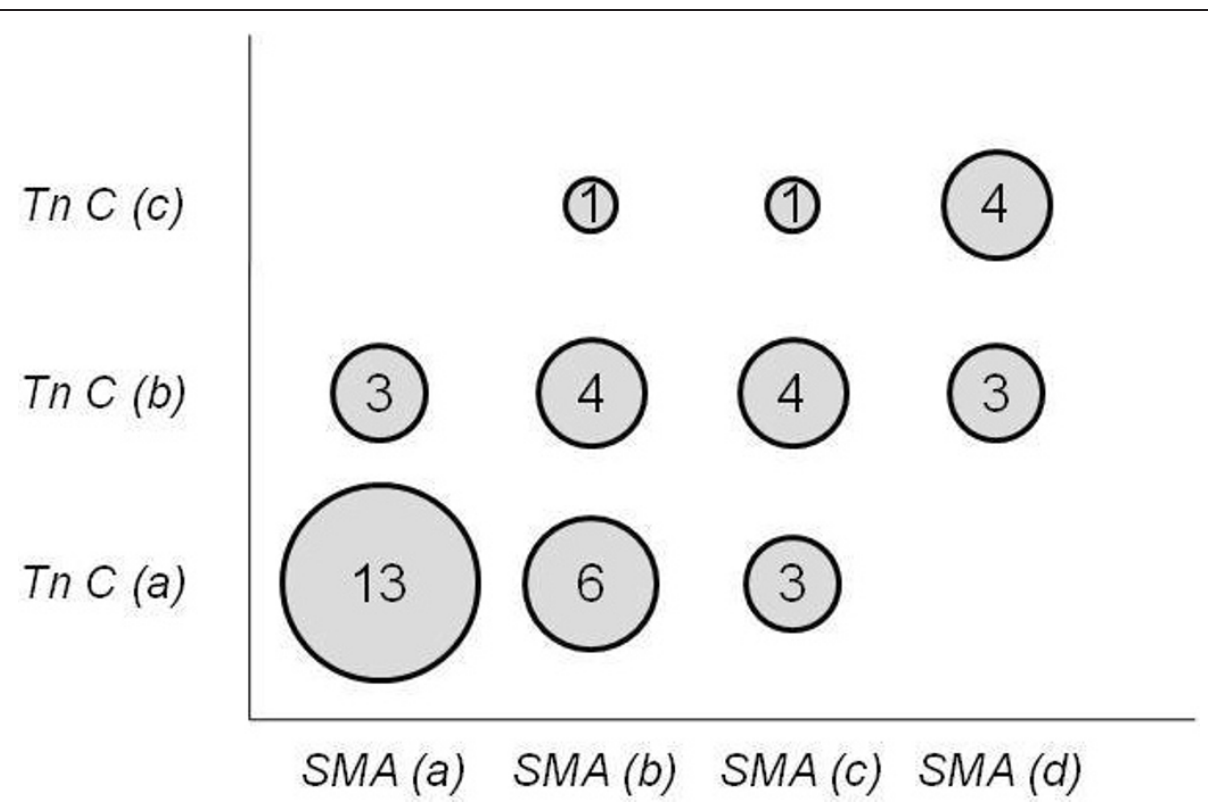

Figure 5 Correlation between staining for Tenascin C and $\alpha$-SMA in all subjects. Increasing degree of staining is indicated by categories $a$ $c$ and $a-d$. Number in the circles indicate number of subjects. The estimate for the correlation coefficient was $0.6 ; \mathrm{P}<0.0001$. 
We were also able to show that biopsies from every subject displayed a positive immunohistochemical expression for $\mathrm{Tn}-\mathrm{C}$ at least around basal cells of the bronchial epithelium, a somewhat novel finding since Tn-C has not regularly been shown to be expressed in normal adult lung tissue. The results of our study might signify that there is some constitutional expression of Tn-C in basal epithelial cells of the human bronchus. In our previous studies in normal developing human lung the expressions of $\mathrm{Tn}-\mathrm{C}$ protein and mRNA were increased during early developmental stages, and decreasing in the end of gestation [23]. In the normal adult human lung $\mathrm{Tn}-\mathrm{C}$ expression was observed to be very sparse [40], although in our earlier studies we focused mainly on the alveolar level, not the central airways. However, the enhanced $\mathrm{Tn}-\mathrm{C}$ expression, co-localized with the expression of myofibroblasts, has been observed in small airways i.e. bronchioles of human lung in neonatal disorders such as respiratory distress syndrome (RDS) and bronchopulmonary dysplasia (BPD) [37].

Both in pulmonary fibrosis and during lung development $\alpha$-SMA positive spindle shaped cells, which were obviously myofibroblasts, seemed to be the main source of mRNA of Tn-C by in situ hybridization method $[22,23,37]$. Myofibroblasts were initially defined in ultrastructural terms, with the essential features of intracellular fibers, which are positive for $\alpha$-SMA, which is nowadays the most common, yet not specific, marker for a myofibroblast $[24,41]$. The origin of myofibroblasts is still unclear. In our earlier studies human lung fibroblasts were differentiated into myofibroblasts by exposing cells to transforming growth factor beta (TGF- $\beta$ ). We observed that ultrastructural features of myofibroblasts were detected after exposure, e.g. $\alpha$-SMA positive bundles in the cytoplasm of cells, extracellular fibronectin-containing structures on the surface of the cell, and extracellular Tn-C in the vicinity of the cell [38]. Myofibroblasts seemed to have a role of the remodelling process of airways in asthmatic lung at least in animal and experimental models $[42,43]$, but not much is currently known about the expression profile and function of myofibroblasts in COPD. To our knowledge this is the first study showing that $\alpha$-SMA positive cells, which might be myofibroblasts, are increased in the airways of the patients with COPD, and moreover, the number of myofibroblasts correlated with the amount of Tn-C. The results suggest that most $\alpha$-SMA positive cells revealed typical expression profile of myofibroblast being positive for $\alpha$-SMA, vimentin and negative for desmin. In the minority of cases the $\alpha$-SMA positive cells were positive also for desmin, which may suggest the other known phenotype for myofibroblast [25]. Interestingly, $\alpha$-SMA positive cells were not present in every patient, whereas
Tn-C positivity, at least in basal epithelial cells, was observed in every patient studied, which may indicate that the basal cells might be able to produce $\mathrm{Tn}-\mathrm{C}$ in large airways even in healthy lung, and that myofibroblasts may be responsible for the production of the excess of $\mathrm{Tn}-\mathrm{C}$ in patients with COPD.

The clinical relevance of our finding can only be speculated. Hypothetically, increased ECM deposition in the large airways in our COPD patients may contribute to airways obstruction. It is, however believed that the major site of airways obstruction in COPD is in the small airways and increased airway wall thickness has been shown to correlate with $\operatorname{FEV}_{1}[9,44]$. It is therefore likely to believe that the COPD patients in the present study also have features of remodeling in the small airways and probably also emphysema. Studies evaluating both large and small airways in a well characterized patient material should therefore be encouraged.

In conclusion, patients with COPD, but not smokers, have signs of airway remodelling in the large airways as measured as an increased expression of $\mathrm{Tn}-\mathrm{C}$ and $\alpha$ SMA positive cells which were obviously myofibroblasts. The finding may represent processes leading to structural changes in the airway wall causing lung function impairment in COPD.

\section{Acknowledgements}

The authors would like to acknowledge Heléne Blomqvist, Margitha Dahl, Benita Dahlberg, Gunnel de Forest, Erja Tomperi, Mirja Vahera and Hannu Wäänänen for excellent technical assistance.

This study was supported by the Swedish Heart-Lung Foundation, King Gustaf V's and Queen Victoria's Freemasons 'Foundation, King Oscar II Jubilee Fund, the Hesselmans Foundation, Karolinska Institutet, the Stockholm City Council, the Academy of Finland, the Jalmari and Rauha Ahokas Foundation, the Finnish Anti-Tuberculosis Association Foundation, the Duodecim of Oulu and the state subsidy for the University Hospital of Oulu.

\section{Author details}

'Dept Medicine, Division of Respiratory Medicine, Karolinska Institutet, Karolinska University Hospital Solna. Stockholm Sweden. ${ }^{2}$ Inst of Clinical Medicine, Dept of Internal Medicine/Respiratory Research Unit, Centre of Excellence in Research, University of Oulu and Oulu University Hospital, Oulu, Finland. ${ }^{3}$ Department of Pathology, Oulu University Hospital and Institute of Diagnostics, Department of Pathology, University of Oulu, Finland.

\section{Authors' contributions}

$\mathrm{ML}$ was corresponding author, enrolled and characterized study participants, performed bronchoscopies and drafted the manuscript, RK and ELB performed all immunohistochemical analyses and evaluations, and participated in writing the manuscript, GT performed statistical analyses and participated in writing the manuscript, MS initiated the project, participated in its design and coordination, performed bronchoscopies, and participated in writing the manuscript. All authors read and approved the final manuscript.

\section{Conflict of Interest disclosures}

The authors declare that they have no competing interests.

Received: 29 September 2010 Accepted: 15 April 2011

Published: 15 April 2011 


\section{References}

1. Murray CJ, Lopez AD: Alternative projections of mortality and disability by cause 1990-2020: Global Burden of Disease Study. Lancet 1997, 349:1498-1504.

2. Lindberg A, Bjerg A, Ronmark E, Larsson LG, Lundback B: Prevalence and underdiagnosis of COPD by disease severity and the attributable fraction of smoking Report from the Obstructive Lung Disease in Northern Sweden Studies. Respir Med 2006, 100:264-272.

3. Buist AS, McBurnie MA, Vollmer WM, Gillespie S, Burney P, Mannino DM, Menezes AM, Sullivan SD, Lee TA, Weiss KB, Jensen RL, Marks GB, Gulsvik A, Nizankowska-Mogilnicka $\mathrm{E}$ : International variation in the prevalence of COPD (the BOLD Study): a population-based prevalence study. Lancet 2007, 370:741-750.

4. Global Initiative for Chronic Obstructive Lung Disease. Global strategy for the diagnosis, management, and prevention of chronic obstructive pulmonary disease. [http://www.goldcopd.com/GuidelinesResources.asp].

5. Di Stefano A, Caramori G, Ricciardolo FL, Capelli A, Adcock IM, Donner CF: Cellular and molecular mechanisms in chronic obstructive pulmonary disease: an overview. Clin Exp Allergy 2004, 34:1156-1167.

6. O'Donnell R, Breen D, Wilson S, Djukanovic R: Inflammatory cells in the airways in COPD. Thorax 2006, 61:448-454.

7. Sullivan AK, Simonian PL, Falta MT, Mitchell JD, Cosgrove GP, Brown KK, Kotzin BL, Voelkel NF, Fontenot AP: Oligoclonal CD4+ T cells in the lungs of patients with severe emphysema. Am J Respir Crit Care Med 2005, 172:590-596.

8. Vignola AM, Chanez P, Chiappara G, Merendino A, Pace E, Rizzo A, la Rocca AM, Bellia V, Bonsignore G, Bousquet J: Transforming growth factorbeta expression in mucosal biopsies in asthma and chronic bronchitis. Am J Respir Crit Care Med 1997, 156:591-599.

9. Hogg JC, Chu F, Utokaparch S, Woods R, Elliott WM, Buzatu L, Cherniack RM, Rogers RM, Sciurba FC, Coxson HO, Pare PD: The nature of small-airway obstruction in chronic obstructive pulmonary disease. $\mathrm{N}$ Engl J Med 2004, 350:2645-2653.

10. Roche WR, Beasley R, Williams JH, Holgate ST: Subepithelial fibrosis in the bronchi of asthmatics. Lancet 1989, 1:520-524.

11. Bourdin A, Neveu D, Vachier I, Paganin F, Godard P, Chanez P: Specificity of basement membrane thickening in severe asthma. J Allergy Clin Immunol 2007, 119:1367-1374.

12. Minshall EM, Leung DY, Martin RJ, Song YL, Cameron L, Ernst P, Hamid Q: Eosinophil-associated TGF-beta1 mRNA expression and airways fibrosis in bronchial asthma. Am J Respir Cell Mol Biol 1997, 17:326-333.

13. Chetta A, Foresi A, Del Donno M, Bertorelli G, Pesci A, Olivieri D: Airways remodeling is a distinctive feature of asthma and is related to severity of disease. Chest 1997, 111:852-857.

14. Jeffery PK: Remodeling and inflammation of bronchi in asthma and chronic obstructive pulmonary disease. Proc Am Thorac Soc 2004, 1:176-183.

15. Liesker JJ, Ten Hacken NH, Zeinstra-Smith M, Rutgers SR, Postma DS, Timens W: Reticular basement membrane in asthma and COPD: similar thickness, yet different composition. Int J Chron Obstruct Pulmon Dis 2009, 4:127-135

16. Roberts $C R$, Burke AK: Remodelling of the extracellular matrix in asthma: proteoglycan synthesis and degradation. Can Respir J 1998, 5:48-50.

17. Laitinen A, Altraja A, Kampe $M$, Linden M, Virtanen I, Laitinen LA: Tenascin is increased in airway basement membrane of asthmatics and decreased by an inhaled steroid. Am J Respir Crit Care Med 1997, 156:951-958

18. Soini Y, Paakko P, Nuorva K, Kamel D, Linnala A, Virtanen I, Lehto VP. Tenascin immunoreactivity in lung tumors. Am J Clin Pathol 1993, 100:145-150

19. Kaarteenaho-Wiik R, Sademies O, Paakko P, Risteli J, Soini Y: Extracellular matrix proteins and myofibroblasts in granulomas of sarcoidosis, atypical mycobacteriosis, and tuberculosis of the lung. Hum Pathol 2007, 38:147-153.

20. Kaarteenaho R, Sormunen R, Paakko P: Variable expression of tenascin-C, osteopontin and fibronectin in inflammatory myofibroblastic tumour of the lung. APMIS 2010, 118:91-100.

21. Calverley P, Pauwels Dagger R, Lofdahl CG, Svensson K, Higenbottam T, Carlsson LG, Stahl E: Relationship between respiratory symptoms and medical treatment in exacerbations of COPD. Eur Respir J 2005, 26:406-413.
22. Paakko P, Kaarteenaho-Wiik R, Pollanen R, Soini $Y$ : Tenascin mRNA expression at the foci of recent injury in usual interstitial pneumonia. Am J Respir Crit Care Med 2000, 161:967-972.

23. Kaarteenaho-Wiik R, Kinnula V, Herva R, Paakko P, Pollanen R, Soini Y: Distribution and mRNA expression of tenascin- $C$ in developing human lung. Am J Respir Cell Mol Biol 2001, 25:341-346.

24. Gabbiani G, Ryan GB, Majne G: Presence of modified fibroblasts in granulation tissue and their possible role in wound contraction. Experientia 1971, 27:549-550.

25. Schurch W, Seemayer TA, Gabbiani G: The myofibroblast: a quarter century after its discovery. Am J Surg Pathol 1998, 22:141-147.

26. Kawka DW, Kazazis DM, Clark RA: In vivo co-distribution of fibronectin and actin fibers in granulation tissue: immunofluorescence and electron microscope studies of the fibronexus at the myofibroblast surface. J Cell Biol 1984, 98:2091-2106.

27. Vancheri C, Failla M, Crimi N, Raghu G: Idiopathic pulmonary fibrosis: a disease with similarities and links to cancer biology. Eur Respir J 2010, 35:496-504.

28. Chaponnier C, Gabbiani G: Pathological situations characterized by altered actin isoform expression. J Pathol 2004, 204:386-395.

29. Wick MR, Hormnick JL: Immunohistology of soft tissue and osseous neoplasms. In Diagnostic Immunohistochemistry.. 3 edition. Edited by: Dabbs DJ. Saunders Elsevier; 2010:84

30. Dellagi K, Brouet JC: Redistribution of intermediate filaments during capping of lymphocyte surface molecules. Nature 1982, 298:284-286.

31. Kranenburg AR, Willems-Widyastuti A, Moori WJ, Sterk PJ, Alagappan VK, de Boer WI, Sharma HS: Enhanced bronchial expression of extracellular matrix proteins in chronic obstructive pulmonary disease. Am J Clin Pathol 2006, 126:725-735.

32. Gosselink JV, Hayashi S, Elliott WM, Xing L, Chan B, Yang L, Wright C, Sin D, Pare PD, Pierce JA, Pierce RA, Patterson A, Cooper J, Hogg JC: Differential expression of tissue repair genes in the pathogenesis of chronic obstructive pulmonary disease. Am J Respir Crit Care Med 2010, 181:1329-1335.

33. Degen M, Goulet S, Ferralli J, Roth M, Tamm M, Chiquet-Ehrismann R: Opposite effect of fluticasone and salmeterol on fibronectin and tenascin-C expression in primary human lung fibroblasts. Clin Exp Allergy 2009, 39:688-699.

34. Harju T, Kinnula VL, Paakko P, Salmenkivi K, Risteli J, Kaarteenaho R: Variability in the precursor proteins of collagen I and III in different stages of COPD. Respir Res 2010, 11:165.

35. Lambert RK, Wiggs BR, Kuwano K, Hogg JC, Pare PD: Functional significance of increased airway smooth muscle in asthma and COPD. J Appl Physiol 1993, 74:2771-2781

36. Lofdahl JM, Cederlund K Nathell L, Eklund A Skold CM: Bronchoalveolar lavage in COPD: fluid recovery correlates with the degree of emphysema. Eur Respir J 2005, 25:275-281.

37. Kaarteenaho-Wiik R, Kinnula VL, Herva R, Soini Y, Pollanen R, Paakko P. Tenascin- $C$ is highly expressed in respiratory distress syndrome and bronchopulmonary dysplasia. J Histochem Cytochem 2002, 50:423-431.

38. Kaarteenaho-Wiik R, Paakko P, Sormunen R: Ultrastructural features of lung fibroblast differentiation into myofibroblasts. Ultrastruct Pathol 2009 33:6-15.

39. Jeffery $P$, Holgate $S$, Wenzel S: Methods for the assessment of endobronchial biopsies in clinical research: application to studies of pathogenesis and the effects of treatment. Am J Respir Crit Care Med 2003, 168:51-17.

40. Kaarteenaho-Wiik R, Tani T, Sormunen R, Soini Y, Virtanen I, Paakko P. Tenascin immunoreactivity as a prognostic marker in usual interstitial pneumonia. Am J Respir Crit Care Med 1996, 154:511-518.

41. Eyden B: Electron microscopy in the study of myofibroblastic lesions. Semin Diagn Pathol 2003, 20:13-24.

42. Michalik M, Pierzchalska M, Legutko A, Ura M, Ostaszewska A, Soja J, Sanak M: Asthmatic bronchial fibroblasts demonstrate enhanced potential to differentiate into myofibroblasts in culture. Med Sci Monit 2009, 15:BR194-201.

43. Miller M, Cho JY, McElwain K, McElwain S, Shim JY, Manni M, Baek JS, Broide DH: Corticosteroids prevent myofibroblast accumulation and airway remodeling in mice. Am J Physiol Lung Cell Mol Physiol 2006, 290: L162-169. 
44. Hogg JC, Macklem PT, Thurlbeck WM: Site and nature of airway obstruction in chronic obstructive lung disease. N Engl J Med 1968, 278:1355-1360.

doi:10.1186/1465-9921-12-48

Cite this article as: Löfdahl et al: Tenascin- $C$ and alpha-smooth muscle actin positive cells are increased in the large airways in patients with COPD. Respiratory Research 2011 12:48.

Submit your next manuscript to BioMed Central and take full advantage of:

- Convenient online submission

- Thorough peer review

- No space constraints or color figure charges

- Immediate publication on acceptance

- Inclusion in PubMed, CAS, Scopus and Google Scholar

- Research which is freely available for redistribution 